\title{
Endoscopic retrograde cholangiopancreatography for treatment biliopleural fistulas
}

\author{
Uso de colangiopancreatografía retrógrada endoscópica en pacientes con fístula biliopleural
}

Edson R. Marcos-Ramírez*, Alejandra Téllez-Aguilera, Martín A. Ramírez-Morín, María I. Treviño-Martínez, Francisco Vásquez-Fernández, Marco A. Hernández-Guedea, and Gerardo Muñóz- Maldonado

Service of General Surgery, Hospital Universitario "Dr. José Eleuterio González”, Universidad Autónoma de Nuevo León, Monterrey, Nuevo León, Mexico

\begin{abstract}
Background: Biliopleural fistula is a rare communication between the biliary system and the pleural space secondary to ruptured hydatid cysts, hepatobiliary surgeries or penetrating wounds. There is not so much of the subject in the literature, so there is no standardized protocol for its management. Objective: The objective of this work is to determine advantages and disadvantages of the use of ERCP as a conservative initial treatment for biliopleural fistulas. Method: Our retrospective study included patients with a diagnosis of biliopleural fistula who underwent ERCP as initial treatment, older than 18 years in a period from August 2016 to August 2019. Results: Eight patients with a diagnosis of biliopleural fistula were included, $75 \%$ men and $25 \%$ women with a mean age of 24.5 years; the traumatic etiology was predominant in our group (89\%), the diagnosis was made between days 3 and 14 after chest tube placement and we were successful in treating the fistula with ERCP in $87.5 \%$ of our patients. Conclusions: The use of ERCP as initial treatment for biliopleural fistula should be considered as the initial tool in the algorithm of management of this entity.
\end{abstract}

Key words: Fistula. Biliopleural. Endoscopic retrograde cholangiopancreatography. Complications. Pleural. Biliary.

\section{Resumen}

Antecedentes: La fístula biliopleural es una comunicación poco frecuente entre el sistema biliar y el espacio pleural secundario a ruptura de quistes hidatídicos, cirugías hepatobiliares o heridas penetrantes Existe poco sobre el tema en la literatura por lo que no existe un protocolo estandarizado para su manejo. Objetivo: El objetivo de este trabajo es determinar ventajas y desventajas del uso de CPRE como tratamiento inicial conservador para fístulas biliopleurales. Método: Nuestro estudio retrospectivo incluyó pacientes con diagnóstico de fístula biliopleural quienes fueron sometidos a CPRE como tratamiento inicial, mayores de 18 años en un período de Agosto de 2016 a Agosto de 2019. Resultados: Se incluyeron 8 pacientes con diagnístico de fístula biliopleural, $75 \%$ hombres y $25 \%$ mujeres con una media de edad de 24.5 años; la etiología traumática fue a predominante en nuestro grupo (89\%), el diagnóstico se realizó entre los días 3 y 14 post colocación de sonda torácica y obtuvimos éxito en el tratamiento de la fístula con CPRE en el $87.5 \%$ de nuestros pacientes. Conclusiones: El uso de CPRE como tratamiento inicial para fístula biliopleural debe ser considerada como la herramienta inicial en el algoritmo de manejo de esta entidad.

Palabras clave: Fístula biliopleural. Colangiopancreatografía retrógrada endoscópica. Complicación. Pleura. Biliar.

\section{Correspondence:}

*Edson R. Marcos-Ramírez

Ave. Francisco I Madero, s/n

Mitras Centro

Date of reception: 30-01-2020

Cir Cir. 2021;89(1):89-96

C.P. 64460, Monterrey, N.L., México

Date of acceptance: 03-06-2020

E-mail: ermarcos7@gmail.com

DOI: 10.24875/CIRU.20000055

Contents available at PubMed www.cirugiaycirujanos.com 0009-7411/@ 2020 Academia Mexicana de Cirugía. Published by Permanyer. This is an open access article under the terms of the CC BY-NC-ND license (http://creativecommons.org/licenses/by-nc-nd/4.0/). 


\section{Introduction}

Biliopleural fistula (BPF) is a pathological communication between the biliary tree and the pleural space. There are several causes described in the literature, which we can summarize in 5 groups $^{1-3}$ :

- Congenital

- Infectious (amebic liver abscess, pyogen, etc.)

- Bile duct obstruction (excluding iatrogenic or traumatic causes)

- Traumatic (blunt or penetrating)

- latrogenic (after liver resection, radiofrequency ablation, chest drainage, etc.)

Pathogenesis can be explained by two mechanisms $\mathrm{s}^{3-5}$ : in the first case, bile duct obstruction is the primary cause of BPF formation due to trauma, inflammation, tumors, etc. This obstruction leads to biliary retention, biloma, and an abscess that gradually erodes the diaphragm and creates communication to the pleural space. In the second case, there is no obstruction of the bile duct, but if the presence of a diaphragmatic/ hepatic erosion, whether inflammatory, infectious, or traumatic that conditions biliopleural communication. In both cases, if there is a previous pulmonary condition that adheres the lung to the parietal pleura (old complicated parapneumonic effusion, empyema, etc.), there is a possibility that the path fistulizes to the bronchial tree and have a bronchobiliary fistula, a rare situation within the entity ${ }^{6}$. In any case, the preferred anatomical point for the formation of this communication is in the posteromedial region of the right hemidiaphragm, a site in contact with the naked area of the liver ${ }^{3,4,6,7}$.

BPF is a rare complication, so there is no epidemiological data on it. Among the most common causes reported in the literature were infectious causes such as liver abscess; however, in recent years, the traumatic cause (mainly penetrating) has been more frequent in the case and series reports (Table 1). In a reference trauma center such as our hospital, the traumatic cause is the most frequent, followed by infectious causes.

The clinical manifestations are described as acute or chronic: the acute event the patient begins with respiratory stress, febrile syndrome, pleuritic pain in the lower portion of the right hemithorax, irritative cough, yellowish sputum in cases of BBPF, and right pleural effusion. The chronic condition is characterized by chronic cough, occasional yellow sputum, intermittent fever, and pneumonia-like conditions ${ }^{8,9}$.
In recent years, conservative treatment has become more important in the treatment and the advent of endoscopic pancreatic cholangiography (endoscopic retrograde cholangiopancreatography [ERCP]) has resulted as an effective element in the treatment of BPF despite the few case series that exist in the literature ${ }^{10,11}$, which is why there are no guidelines for optimal treatment. In this paper, we present the experience of the use of ERCP in patients with BPF treated in our Hospital Universitario "Dr. José Eleuterio González" in the last 3 years.

\section{Materials and methods}

A descriptive retrospective study was carried out, including patients who were detected the presence of fructose bis-phosphate (FBP) for various causes, including penetrating wounds. We obtained the information of clinical records, diagnoses were assessed, characteristics of the lesions, initial repair technique, days of hospital stay, and their outcome after performing all of our ERCP patients. We made a statistical analysis with the JMP 10 program. These patients were in a period from August 2016 to August 2019 in our Hospital Universitario "Dr. José Eleuterio González" in Monterrey, N.L., Mexico.

\section{Results}

We obtained a total of 8 patients with a diagnosis of FBP in a period of 3 years, of which 6 were men (75\%) and 2 women (25\%), with a mean age of 24.5 years. The diagnoses were three in all, traumatic, which we divided into gunshot wound (GSW) and stab wounds and infectious (Fig. 1).

Our 7 trauma diagnosis patients showed a double penetrating lesion, either by a projectile or by a knife, which required a surgical approach; all of them underwent an exploratory laparotomy and only 2 of the 7 trauma patients a concomitant right thoracotomy was required due to the initial trauma, either for the repair of pulmonary lesions or control of chest bleeding. Due to the double penetrating lesion, there was a need for diaphragmatic repair, which debrided the edges in the firearm injuries and performed primary repair of the diaphragm; in one patient, an omentum patch was performed and in the second trauma patient was placed a pleura patch (Table 2). The eighth patient was a female with a diagnosis of pyogenic liver abscess who had her laparotomy abscess drained with an omentum patch placed on the liver bed. 


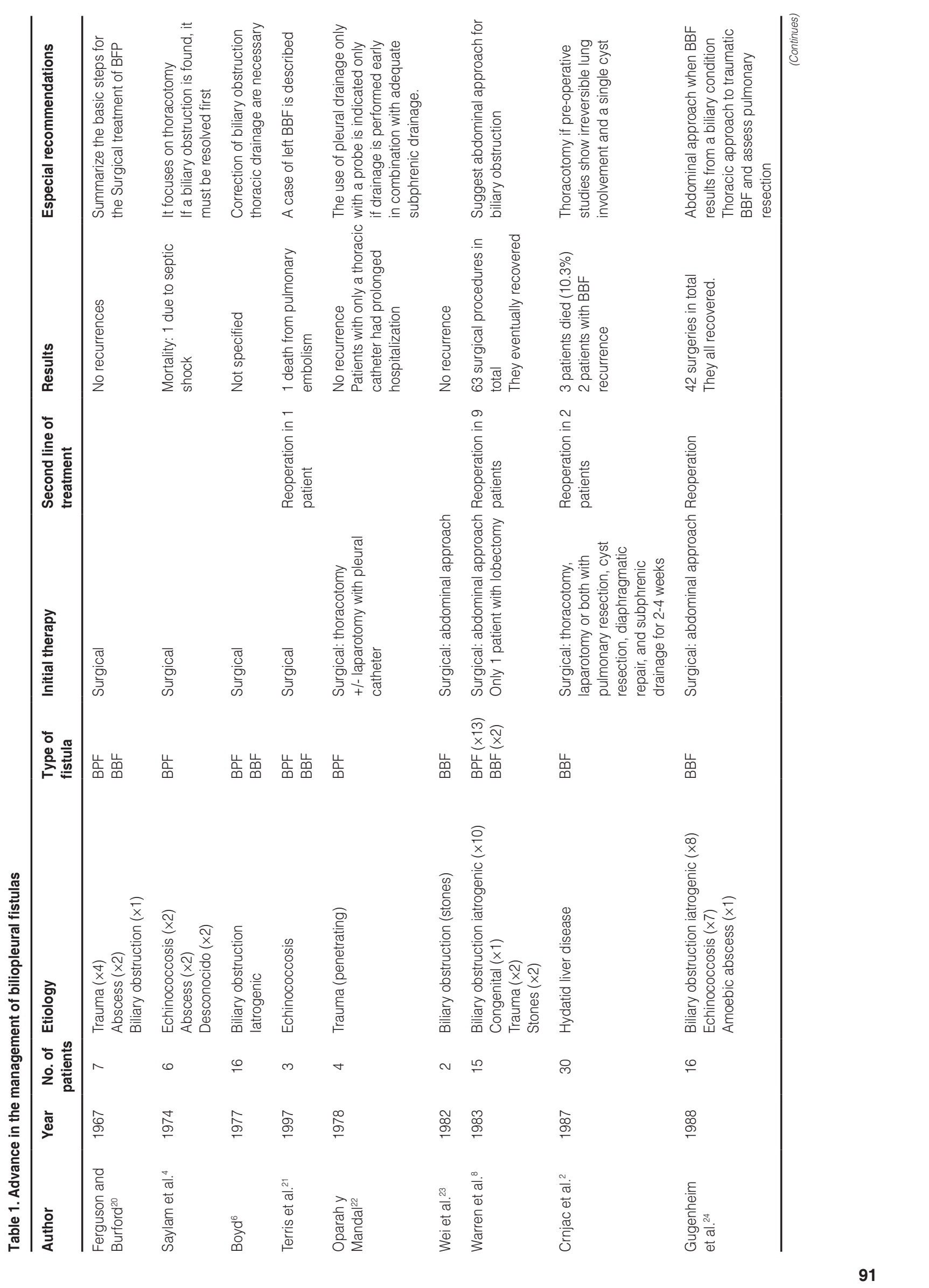




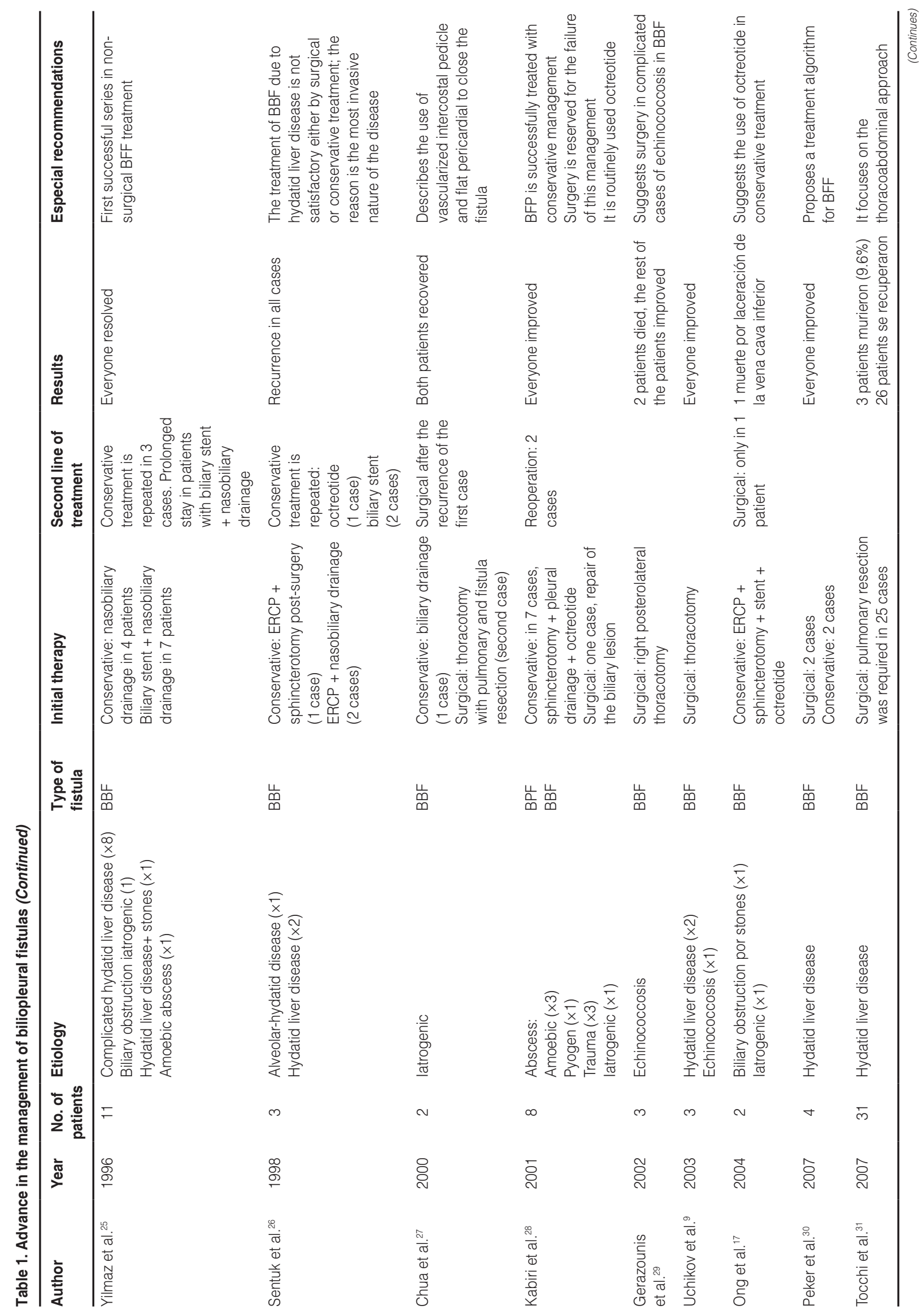




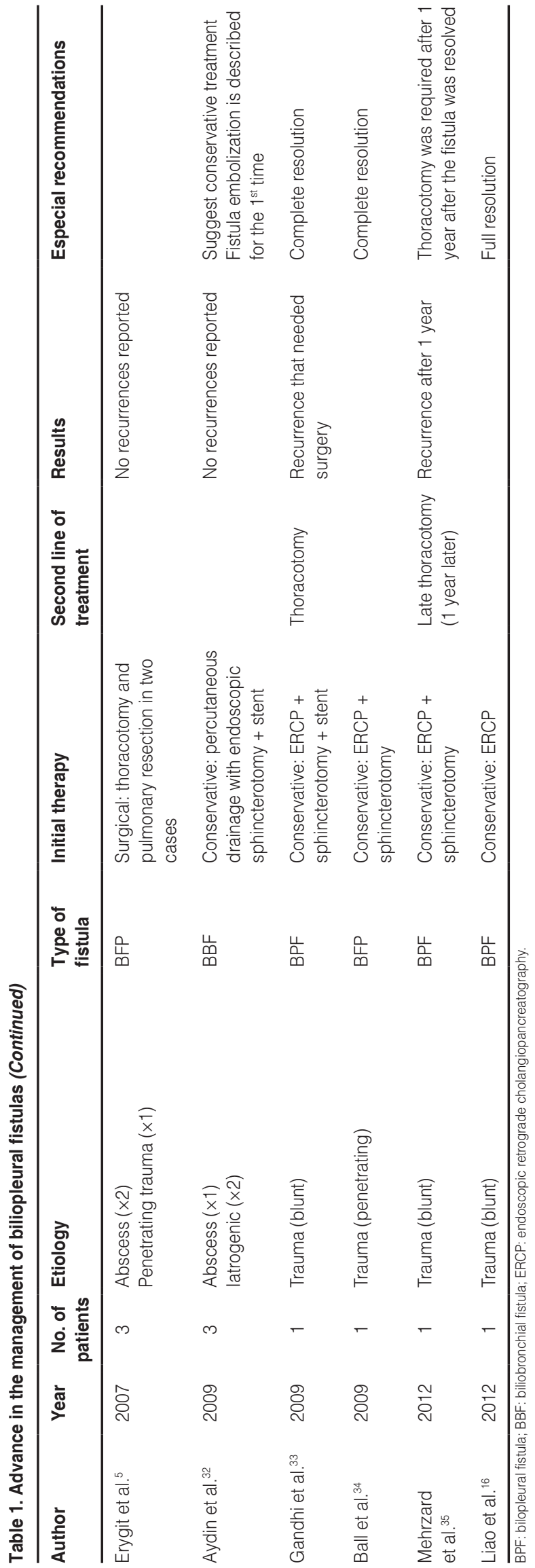

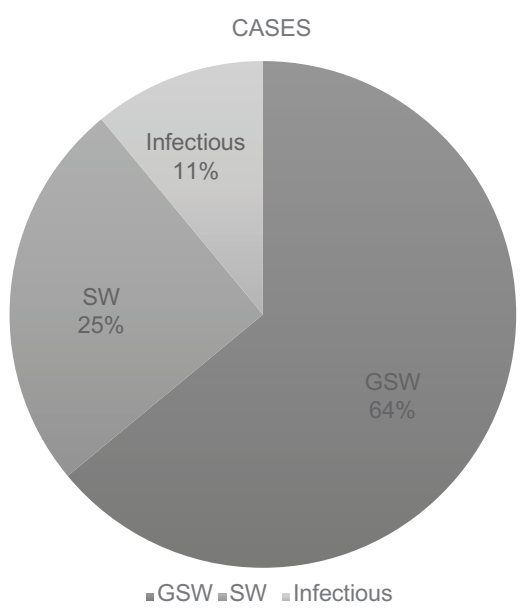

Figure 1. Diagnostics of our population. GSW: gunshot wound, SW: stab wound.

All our patients had a need for the placement of a pleural catheter $(\mathrm{PC})$ from the beginning due to the double penetrating lesion. The outflow of liquid with biliary characteristics was observed by the PC between days 3 and 14 post-placement (mean of 5.7 days); the fistulas recorded an expense of approximately $100 \mathrm{cc}$ of biliary characteristics in $24 \mathrm{~h}$. No other imaging study was performed for diagnosis due to the obvious clinical signs of patients with the presence of right pleural effusion and the characteristics of the fluid drained by the PC. Clinically, patients diagnosed with BPF due to trauma remained hemodynamically stable, with no evidence of systemic inflammatory response; the patient with a diagnosis of liver abscess was detected the presence of BPF at 14 days post-PC placement, remained persistent febrile due to an intra-abdominal collection secondary to her diagnosis, which was evacuated by punction; however, the patient was complicated with intrahospital pneumonia which culminated in her death.

All of our patients underwent ERCP with sphincterotomy between days 2 and 10 after diagnosis of BPF (mean of 4.3 days). Once the procedure was performed, we obtained the resolution of the BPF in 7 of 8 patients $(87.5 \%)$. We define as a response to treatment the decrease in the biliary expenditure by the thoracic catheter to $<10 \mathrm{cc}$ in $24 \mathrm{~h}$ with radiological evidence of little or no residue in the pleural cavity, which was obtained from these 7 patients between days 3 and 5 post-ERCP (average of 3.12 days). No complications of ERCP were reported.

We had mortality in 2 patients which are worth analyzing in detail: the first patient who died was a GSW 
Table 2. Population with their initial diagnoses, initial surgery, and type of diaphragmatic repair

\begin{tabular}{|c|c|c|c|c|}
\hline Patient & Diagnosis & Injuries & Surgery & Repair \\
\hline 1 & GSW & $\begin{array}{l}\text { Liver injury SII + Intestinal injury SIII + } \\
\text { intercostal laceration }\end{array}$ & $\begin{array}{l}\text { Laparotomy + Right } \\
\text { thoracotomy }\end{array}$ & Primary + pleural patch \\
\hline 2 & GSW & Liver injury SIII & Laparotomy & Primary \\
\hline 3 & GSW & Liver injury SII & Laparotomy & Primary + omentum patch \\
\hline 4 & SW & Liver injury SII & Laparotomy & Primary \\
\hline 5 & GSW & $\begin{array}{l}\text { Liver injury SIII + colon lesion SII + } \\
\text { Intercostal artery laceration }\end{array}$ & $\begin{array}{l}\text { Laparotomy + Right } \\
\text { thoracotomy }\end{array}$ & Primary \\
\hline 6 & GSW & Liver injury SII+ lung laceration & $\begin{array}{l}\text { Laparotomy + Right } \\
\text { thoracotomy }\end{array}$ & Primary \\
\hline 7 & SW & Liver injury SIII & Laparotomy & Primary \\
\hline 8 & Pyogenic liver abscess & Does not apply & Laparotomy & Primary + omentum patch* \\
\hline
\end{tabular}

Firearm projectile wound (GSW), puncture wound (SW), injury stage (S). * This patient underwent surgical drainage of the liver abscess and the omentum patch was placed on the liver bed; GSW: gunshot wound, SW: stab wound.

in which, in his associated lesions, a colon lesion was detected; in his post-operative, the patient was complicated with the presence of BPF which was detected on the $5^{\text {th }}$ day after PC placement, ERCP was performed on the $10^{\text {th }}$ day (ERCP delayed due to poor patient conditions) and we obtained a response to appropriate BPF treatment on the $5^{\text {th }}$ day after ERCP; however, the patient's conditions did not improve and finally the patient dies from sepsis. The second case was a patient with a diagnosis of pyogenic liver abscess who was referred to our hospital with PC and for follow-up. We detect the presence of BPF on the $14^{\text {th }}$ day after PC; late ERCP is performed due to poor conditions of the patient (on the $6^{\text {th }}$ day after diagnosis); however, due to abdominal sepsis knotted to a diagnosis of hospital-acquired pneumonia, the patient passes away.

At present, at long-term follow-up, the 6 patients in whom we obtained a good response to ERCP treatment remained uncomplicated, these patients had PC withdrawn, major surgery was avoided, and no inflammatory response data were discharged for follow-up at the office. During his surveillance, there was no evidence of a recurrence of pleural effusion, an increase in bilirubin, or leukocytosis, so they were definitively discharged from the consultation.

\section{Discussion}

The presence of BPF is a low-frequency entity, as we saw reported in the literature, the infectious cause was the first cause described; however, in the most recent reviews, the penetrating traumatic cause is the one that currently prevails, probably due to the change in society and the current problems that we face and that we could verify in our study ${ }^{5,12-16}$. Its treatment begins from the early diagnosis, preventing the increase and complications of the BPF itself because the bile fluid it has a corrosive potential on the lung and pleu$\mathrm{ra}^{11,13}$. That is why a high degree of clinical suspicion is mandatory in its management.

Due to the analysis of the experience obtained in our study and compared to that described in the international literature, we propose standardization in the treatment of BPF. Once the presence of BPF has been demonstrated, it is proposed to start with conservative management, which consists of the use of intravenous antibiotics, low-fat diet, analyze the use of somatosta$\operatorname{tin}^{17}$, and liver ultrasound with right pleural space screening in which it can be identified pleural effusion and/or the presence of right subdiaphragmatic collection, so the PC is placed for pleural effusion and/or percutaneous drainage for intra-abdominal collections. The persistence of bile fluid by the PC dictates the need to assess the use of ERCP. This procedure is beneficial due to its potential diagnosis when performing an endoscopic and subsequently therapeutic cholangiography; considering the principle of any fistula, ERCP with sphincterotomy will reduce the distal resistance of the sphincter of Oddi which is around $18 \pm 2 \mathrm{mmHg}$, in addition to the normal pressure of the common duct which is between $10 \pm 2 \mathrm{mmHg}$, this pressure gradient will be 


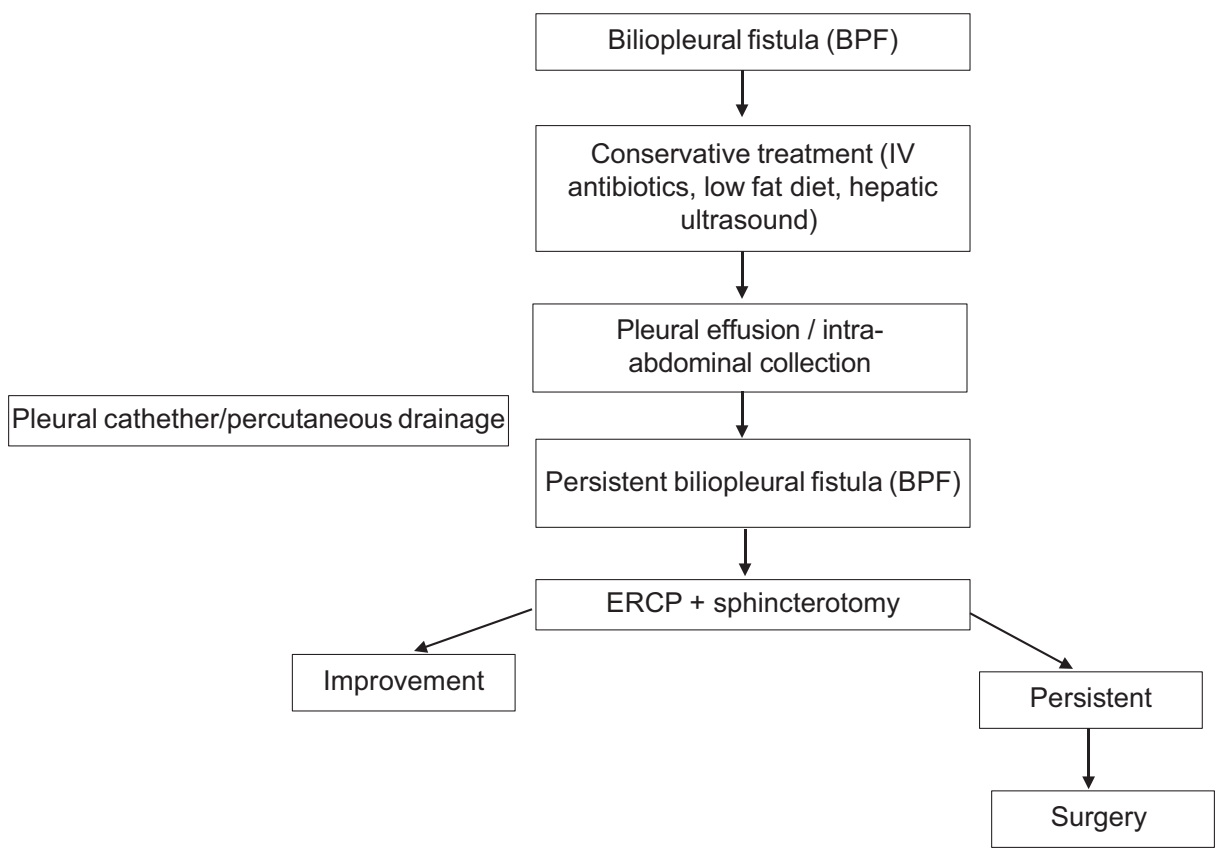

Figure 2. Algorithm proposed for the management of biliopleural fistula.

reduced to $1 \pm 1 \mathrm{mmHg}$ after a spherotomy ${ }^{18}$. Due to this principle, ERCP with sphincterotomy is recommended within 72-96 $\mathrm{h}$ after PC placement and persistence of bile fluid outflow. It is expected to have BPF resolution within the first $48 \mathrm{~h}^{11}$. This conservative management does not increase the morbidity that surgical treatment entails. The pharmacological agents that reduce the pressure of the sphincter of Oddi have been proposed; however, their role in the management of BPF is unclear ${ }^{19}$. The percentage of success reported in the literature is close to $97 \%$ of cases, and the rest of patients culminate in the need for surgical treatment. That is why a BPF management algorithm is proposed (Fig. 2). In studies published in the literature, it does not dictate a difference between results according to cause (infectious vs. traumatic); in this series of cases, we found traumatic as the most frequent cause; however, we obtained an infectious cause in which he died of sepsis. It is important to note that the infectious origin of this entity is much more infrequent, that is why infectious versus traumatic analysis is difficult.

\section{Conclusion}

This study tries to be an initiator in the treatment of a very infrequent complication; its rarity is reflected in the few patients that were obtained in 3 years in a reference center in our country; however, good results were obtained with this observational study. This management algorithm is proposed to carry out prospective studies once this entity that is little described has been identified.

The importance of the benefit of biliary decompression in BPF is important, showing that it significantly reduces the morbidity and mortality offered by surgical treatment. The recommended time to perform it is 72-96 $\mathrm{h}$ after diagnosis of BPF when the patient's clinical conditions allow it; in this way, it has found the benefits of avoiding surgical treatment (intra-hospital days, costs, etc.).

Our series is the largest reported in the literature in recent years, which was treated with conservative management based on ERCP and sphincterotomy for BPF, obtaining promising results and promoting the use of this management algorithm in our center and serving as a basis for long-term prospective comparative studies.

\section{Acknowledgment}

Our deepest thanks to our patients, who are the first teachers on stage.

\section{Conflicts of interest}

There are no conflicts of interest between the proponents and participants in the present work. 


\section{Ethical disclosures}

Protection of human and animal subjects. The authors declare that no experiments were performed on humans or animals for this study.

Confidentiality of data. The authors declare that they have followed the protocols of their work center on the publication of patient data.

Right to privacy and informed consent. The authors declare that no patient data appear in this article.

\section{References}

1. Navsaria PH, Adams S, Nicol AJ. Traumatic thoracobiliary fistulae: a case report with a review of the current management options. Injury. 2002;33:639-43.

2. Crnjac A, Pivec V, Ivanecz A. Thoracobiliary fistulas: literature review and a case report of fistula closure with omentum majus. Radiol Oncol. 2013;47:77-85.

3. Adams HD. Pleurobiliary and bronchobiliary fistulas. J Thorac Surg. 1955;30:255-62.

4. Saylam A, Ersoy Ü, Baris I, Artvinli M, Bozer AY. Thoracobiliary fistulas: report of six cases. Br J Dis Chest. 1974;68:264-72.

5. Eryigit $\mathrm{H}$, Oztas S, Urek S, Olgac G, Kurutepe M, Kutlu CA. Management of acquired bronchobiliary fistula: 3 case reports and a literature review. J Cardiothorac Surg. 2007;2:1-4.

6. Boyd DP. Bronchobiliary and bronchopleural fistulas. Ann Thorac Surg. 1977;24:481-7.

7. Vásquez CS, Velásquez GM, Miranda EL, Ramírez VJ, Corona CF, Alcántara MF, et al. Fístula tramática toracobiliar. Cir Gen. 2006;28(1):5456.

8. Warren KW, Christophi C, Armendariz R, Basu S. Surgical treatment of bronchobiliary fistulas. Surg Gynecol Obs. 1983;4:361-366.

9. Uchikov AP, Safev GP, Stefanov CS, Markova DM. Surgical treatment of bronchobiliary fistulas due to complicated echinococcosis of the liver: case report and literature review. Folia Med. 2003;4:22-4.

10. Thrumurthy SG, Anuruddha AH, De Zoysa MI, Samarasekera DN. ERCP for the treatment of traumatic biliobronchial and biliocutaneous fistulas. Endoscopy. 2011;43 Suppl 2:E42.

11. Singh B, Moodley J, Sa FC, Dhooma N. Conservative management of thoracobiliary fistula. 2002;4975:2-5.

12. Banerjee N, Rattan A, Priyadarshini P, Kumar S. Post-traumatic bronchobiliary fistula. BMJ Case Rep. 2019;12:12-5.

13. Thorac A. Conservative management of a bilothorax resulting from blunt hepatic trauma. Ann Thorac Surg. 2012:93:2043-4.
14. Lim KH, Park J. Blunt traumatic diaphragmatic rupture. Medicine (Baltimore). 2018;97:e12849.

15. Nikumbh TN, Barot PV, Kurlekar UA, Bapaye AM. Endoscopic management of bilio-pleural fistula following thoracoabdominal trauma. OGH Reports. 2018;7(1):67-9.

16. Liao GQ, Wang $\mathrm{H}, \mathrm{Hu} \mathrm{QH}$, Tai $\mathrm{S}$. A successful treatment of traumatic bronchobiliary fistula by endoscopic retrograde biliary drainage. Chin $\mathrm{J}$ Traumatol. 2012:15:59-61.

17. Ong M, Moozar K, Cohen LB. Octreotide in bronchobiliary fistula management. Ann Thorac Surg. 2004;4:1512-5.

18. Goff JS. The human sphincter of oddi: physiology and pathophysiology. Arch Intern Med. 1988;148:2673-7.

19. Hoffman BJ, Cunningham JT, Marsh WH. Endoscopic management of biliary fistulas with small caliber stents. Am J Gastroenterol. 1990;85:705-7.

20. Ferguson TB, Burford TH. Pleurobiliary and bronchobiliary fistulas: surgical management. Arch Surg. 1967;95:380-6.

21. Tierris EJ, Avgeropoulos K, Kourtis K, Papaevangelou EJ. Bronchobiliary fistula due to echinococcosis of the liver. World J Surg. 1977:1:99-104.

22. Oparah SS, Mandal AK. Traumatic thoracobiliary (pleurobiliary and bronchobiliary) fistulas. J Trauma Inj Infect Crit Care. 1978;18:539-44.

23. Wei WI, Choi TK, Wong J, Ong GB. Bronchobiliary fistula due to stones in the biliary tree: report of two cases. World J Surg. 1982;6:782-4.

24. Gugenheim J, Ciardullo M, Traynor O, Bismuth $\mathrm{H}$. Bronchobiliary fistulas in adults. Ann Surg. 1988;207:90-4.

25. Yilmaz U, Sahin B, Hilmioglu F, Tezel A, Boyacioglu S CT. Endoscopic treatment of bronchobiliary fistula: report on 11 cases. Hepatogastroenterology. 1996;43:293-300.

26. Senturk H, Mert A, Ersavasti G, Tabak F, Akdogan M, Ulualp K. Bronchobiliary fistula due to alveolar hydatid disease: report of three cases. Am J Gastroenterol. 1998;93:2248-53.

27. Chua HK, Allen MS, Deschamps C, Miller DL, Pairolero PC. Bronchobiliary fistula: principles of managemen. Ann Thorac Surg. 2000;40:1392-4.

28. Kabiri EH, El Maslout A, Benosman A. Thoracic rupture of hepatic hydatidosis (123 cases). Ann Thorac Surg. 2001;72:1883-6.

29. Gerazounis M, Athanassiadi K, Metaxas E, Athanassiou M, Kalantzi N. Bronchobiliary fistulae due to echinococcosis. Eur J Cardiothorac Surg. 2002;22:306-8.

30. Peker Y, Can MF, Genc O, Gozubuyuk A, Zeybek N, Tufan T. Appropriate approach to bronchobiliary fistulas: a case series with hydatid disease and algorithm of case-based management. Int Surg. 2007;4:239-46.

31. Tocchi A, Mazzoni G, Miccini M, Drumo A, Cassini D, Colace L, et al. Treatment of hydatid bronchobiliary fistulas: 30 years of experience. Liver Int. 2007;27:209-14.

32. Aydin U, Yazici P, Tekin F, Ozutemiz O, Coker A. Minimally invasive treatment of patients with bronchobiliary fistula: a case series. J Med Case Rep. 2009;3:1-4

33. Gandhi N, Kent T, Kaban JM, Stone M, Teperman S. Bronchobiliary fistula after penetrating thoracoabdominal. J Trauma 2009;67:143-5.

34. Ball CG, Trexler S, Rajani RR, Vercruysse G, Feliciano DV, Nicholas JM, Importance of liver drainage in biliary-bronchopleural fistula resulting from thoracoabdominal gunshot injury. Can J Sur. 2009;52(1):E12-E13.

35. Mehrzad H, Aziz A, Mangat K. Transhepatic embolisation of a traumatic broncho-biliary fistula: a novel approach. BMJ Case Rep. 2012;2012: bcr2012006702. 